\title{
LA PLURALIDAD HUMANA \\ EN TANTO CONDITIO PER QUAM DE LA VIDA POLÍTICA ${ }^{1}$
}

\author{
Vanessa Kaiser ${ }^{2}$
}

\section{Resumen/Abstract}

A juicio de Tocqueville, la igualdad implica dos tendencias en la democracia; una impulsa directamente a los hombres a la independencia y otra los conduce a la servidumbre, a una igualación que cabe denominar homogeneidad. El artículo tiene por objeto avanzar -desde el pensamiento arendtiano- en el estudio de la homogenización denunciada por Tocqueville. El argumento se divide en dos partes. En la primera, sostiene que la igualdad propiamente política ha colapsado bajo las dinámicas de la homogenización desatada tras el auge de lo social y la consecuente destrucción de la esfera pública denunciados por Arendt. Estamos, en el marco de su teoría, ante la igualdad de los modernos, la cual implica la destrucción de la condición humana de la pluralidad. Luego, en la segunda parte, se explica el vínculo entre la pluralidad, cuya realización está dada por la igualdad, en el primer sentido que le da Tocqueville, y la esfera pública. La tesis plantea que este vínculo es elaborado por Arendt en La condición humana, donde sostiene que la pluralidad es una conditio per qam de la vida política, un rasgo exclusivo del actor político u hombre de acción, la más elevada de las tres condiciones que componen la vita activa.

Palabras clave: igualdad, libertad, servidumbre, espacio público, Tocqueville, Arendt.

THE HUMAN PLURALITY AS A CONDITIO PER QUAM OF POLITICAL LIFE

According to Tocqueville, equality involves two trends in democracy; one drives men directly to independence and the other leads to servitude, to an equalization that may be called homogeneity. The aim of the article is to advance

\footnotetext{
1 El artículo es parte de mi tesis de doctorado en Ciencia Política, titulada Homogeneidad como fundamento del mal político contemporáneo, en proceso.

2 Chilena, Pontificia Universidad Católica de Chile. Email: kaiser.vanessa@gmail.com
} 
the study of Tocqueville's homogenization through Hanna Arendt's thinking. The argument is divided into two parts. In the first part it argues that actual political equality has collapsed under the homogenisation unleashed after the rise of the social and the consequent destruction of the public sphere denounced by Arendt. In the context of her theory, we are facing "modern equality", which involves the destruction of the human condition of plurality. Then in the second part, the link between plurality, whose realization is given by 'equality' in the first sense that Tocqueville describes, and the public sphere, is explained. The thesis argues that this link is worked by Arendt in her book The Human Condition, which states that plurality is conditio per quam from political life, an exclusive feature of the political actor or man of action, the highest of the three conditions that make the vita activa.

Keywords: equality, freedom, servitude, public space, Tocqueville, Arendt.

\section{Homogeneidad, condición necesaria del totalitarismo}

Con el objeto de contextualizar la discusión sobre la igualdad moderna u homogeneidad, hay que tener a la vista las reflexiones que Arendt desarrolla en su obra Sobre la revolución, donde afirma que la antigua isonomía griega garantizaba un tipo de igualdad la cual no respondía al hecho de que los humanos hubiesen nacido o hubieran sido creados iguales. Contrariando la visión de los modernos, la pensadora afirma que, debido a la pluralidad característica de la condición humana- es decir, al hecho de que cada quien es distinto de todos sus congéneres-, fue necesaria aquella igualdad que tiene por fin hacer a los hombres igualesen un sentido estrictamente político (Arendt, 2009: 39). El marco de realización de dicha igualdad fue la polis entendida como una institución artificial que quiebra con el mundo natural en tanto es una creación humana que no responde a las necesidades propias del ciclo biológico ni resulta de las dinámicas del intercambio económico. Así, siguiendo la narración aristotélica sobre la existencia del humano en singular cuyo fin es sostener su ciclo vital, de la familia que sirve los fines privados y de la aldea en cuyo marco se alcanzan los objetivos sociales y comerciales, la pensadora afirma que la vida plural en la que el humano se distingue revelando su unicidad ante los otros, es propia de la polis.

Es desde el discurso y la acción que cada quien aparece frente a los demás en aquel espacio constituido por la polis donde los humanos comparten 
una doble igualdad. Ella refiere a que, por una parte, debido a la condición humana de pluralidad, todos somos iguales pues no existe ni ha existido nunca un humano "igual" a otro. Mientras, por otra parte, alude a la isonomía que, en la antigua Grecia se conferían los ciudadanos unos a otros, asegurando a todos la igual libertad en tanto miembros de la esfera pública. Planteado en otros términos, la igualdad política resultaba de la libertad humana en la medida que era consecuencia de la decisión de considerar al otro un igual y era necesaria porque somos todos distintos. De dicha consideración surge la existencia plural que, a su vez, es constitutiva de la esfera pública en la que cada quien revelaba su unicidad. En palabras de Arendt:

"Pertenecer a los pocos <<iguales〉> (homoioi) significaba la autorización de vivir entre pares; pero la esfera pública, la polis, estaba calada de un espíritu agonal, donde todo individuo tenía que distinguirse constantemente de los demás, demostrar con acciones únicas o logros que era el mejor [...]" (Arendt, 2010: 52).

Lejos de aquellos tiempos, la igualdad de los modernos traza una ruta cuya peligrosidad fue anunciada por Tocqueville y ampliamente descrita por Arendt, quien por su condición de judía en la Alemania nazi, llegó a ser no sólo una de sus observadoras más perspicaces, sino además, una de sus víctimas.

A juicio de la pensadora, bajo la igualdad política que se enarbola en las democracias representativas modernas, todos somos iguales de manera tal que no se percibe la natural diversidad que hace de cada quien un ser único e irrepetible. Estamos ante el fenómeno de la sociedad de masas que exige de sus habitantes un conformismo anclado en el interés común, a partir del cual la vida del humano queda subsumida bajo las leyes estadísticas las cuales anulan la relevancia de toda acción que escape al comportamiento condicionadopor la sociedad (Arendt, 2010: 53-54).

El cuadro se complejiza si se toma en cuenta la desaparición de la esfera pública producto de la victoria de la sociedad. Y es que, en ausencia de un espacio de encuentro que sirva a la acción política y al discurso en los que se revela la unicidad del agente, el humano queda reducido a un haz de reacciones frente a los vaivenes del interés común, siempre anclado en las necesidades del ciclo biológico individual o de las relaciones comerciales. Así, aquella esfera en que se experimentaba la igual libertad a partir de la cual los humanos contribuían desde su singular aporte en acciones con sus iguales, desaparece y con su extinción, comienza la desertificación de la existencia plural que, a juicio de la autora, posibilita el surgimiento de las tormentas totalitarias 
(A rendt, 2008: 225-226). En lo que sigue, explicaré el vínculo entre la igualdad moderna y el totalitarismo.

La hebra desde la cual es posible tejer el argumento que nos permite desarrollar una hermenéutica sobre el vínculo entre ambos fenómenos se encuentra en Los origenes del totalitarismo. En dicha obra, Arendt nos advierte acerca de cier tos "mecanismos ocultos" que habrían sobrevivido a los regímenes totalitarios y podrían conducir - en el marco de las democracias occidentales actuales- al uso de soluciones totalitarias (Arendt, 2001: 26; 616). Mi tesis sostiene que, aunque Arendt no los haya especificado, los mecanismos a los que se refiere, operan homogenizando y su funcionamiento es producto de la forma moderna de entender la igualdad política. Y es que la igualdad de las democracias representativas, al desvincularse de un espacio para su realización y fundarse en el interés común, en lugar de servir como condición de posibilidad de distinción, deja a todos los miembros del artificio en estado de igual irrelevancia y reemplazabilidad. Para designar dicho estado, Arendt, nos recuerda la condición de vida del animal laborans, cuyo rasgo central consiste en el ocultamiento de todo lo que sea la personalidad o carácter de cada ciudadano, es decir, de todo lo que es irrepetible en él. De ahí que la pensadora afirme:

"Dentro de esta sociedad, que es igualitaria porque esa es la manera de hacer que los hombres vivan juntos, no quedan clases, ninguna aristocracia de naturaleza política o espiritual a partir de la que pudiera iniciarse de nuevo una restauración de las otras capacidades del hombre" (Arendt, 2010: 17).

En mi lectura de la obra arendtiana, el problema que representa la homogenización descrita,se desarrolla en torno a tres aspectos fundamentales: sus perniciosos efectos sobre la dignidad, la reclusión del humano a la esfera privada junto a la consecuente destrucción del mundo común y, finalmente, el surgimiento de soluciones totalitarias. En lo que sigue explico cada uno de ellos y el modo en que se vinculan entre sí.

De la lectura de dos pasajes que se encuentran en las obras más importantes de la pensadora (me refiero a Los origenes del totalitarismo y La condición humana) es posible afirmar que dignidad y realización humana de pluralidad son inescindibles. En el primero de ellos, la pensadora afirma que respetar la dignidad humana "implica el reconocimiento de mis semejantes o de las naciones semejantes a la mía, como súbditos, como constructores de mundos o como codificadores de un mundo común” (Arendt, 2001: 615). 
Pero, ¿qué significa dicho reconocimiento?

Lo primero que cabe establecer es que la dignidad sólo sería posible en el marco de la isonomía anteriormente descrita. Ello, debido a que el mundo común es resultado de la decodificación o significación que, sobre los asuntos humanos, hacen los ciudadanos reunidos en la esfera pública. De ahí que la pensadora plantee que nuestra realidad se encuentra asegurada por la presencia de otros que ven y oyen lo que oímos de modo tal que es posible identificar el objeto sobre el cual se despliegan las distintas perspectivas (Arendt, 2010: 60). A partir de dicha identificación -es decir, el que todos entendamos sobre qué estamos hablando cuando, por ejemplo, nos referimos a derechos humanos, igualdad, mesa o espacio-, se constituyen las bases de la realidad. Cabe agregar que, en tanto facultad constitutiva del mundo común, la decodificación engarza con la construcción del artificio, al que cada quien aporta desde su perspectiva singular, es decir, desde el lugar único que cada quien ocupa en el mundo. Planteado en otros términos, en el marco del pensamiento arendtiano puede decirse que cuando el humano es reconocido por su comunidad, desde aquellos rasgos que debido a la condición humana de pluralidad le hacen único e irrepetible, goza de la existencia plural y, en consecuencia, de un mundo al que pertenece. $\mathrm{Y}$ es dicha pertenencia la condición que posibilita la dignidad humana. En contraste, donde el humano haya sido homogeneizado y sus actividades constreñidas a una función de producción, como sucede con el animal laborans (condición de vida propia de las sociedades de masas), éste será reemplazable y, por tanto, se habrá establecido el marco que posibilita su exterminio. En suma, el anonimato que caracteriza al animal laborans cuya existencia transcurre recluido en el aislamiento, carente de esfera pública, nos muestra una vida que se desarrolla bajo la condición de superfluidad o de ausencia de mundo y, consecuentemente, de realidad común.

Un modo de ejemplificar la manera en que la destrucción de la pertenencia al mundo y la imposibilidad de la distinción de cada uno de sus miembros están vinculadas a una vida privada de dignidad, se encuentra en el siguiente pasaje de La condición humana:

"Los monumentos al <<Soldado Desconocido $>>$ levantados tras la Primera Guerra Mundial testimonian la necesidad aún existente entonces de glorificación, de encontrar un <<quién $>>$, un identificable alguien al que hubieran revelado los cuatro años de matanzas. La frustración de ese deseo y la repugnancia a resignarse al hecho brutal de que el agente de la guerra no era realmente nadie, inspiró la erección de los monumentos al $<<$ desconocido $>>$, a todos los que la 
guerra no había dado a conocer, robándoles no su realización, sino su dignidad humana" (Arendt, 2010: 205).

El vínculo entre un humano que carece de dignidad en términos de su desarraigo del mundo y la consecuente condición de vida de superfluidad nos invita a pensar sobre la manera en que se completa el cuadro con los rasgos centrales de un escenario propicio al advenimiento de las soluciones totalitarias. Para un mayor entendimiento del modo de vida característico del humano homogenizado, cabe detenerse en la superfluidad que la pensadora afirma, es condición de la existencia de quienes han sido uniformados y privados de mundo, ya sea por retiro voluntario o por falta de una esfera pública.

La superfluidad es para el individuo lo que la desmundanización es para la durabildad del mundo. Ambos están indisolublemente vinculados y, en los términos del trabajo que presento, cuyo análisis se centra en las sociedades de masas, tanto la desmundanización como la amenaza que acecha la durabilidad de nuestro artificio, son resultado de los mecanismos ocultos o dispositivos homogeneizantes cuyos efectos sobre los individuos se han ido extremando peligrosamente.

La Época Moderna en cuyo marco el humano vive desarraigado del mundo, se muestra, bajo un prisma arendtiano, como una etapa de intensificación de las dinámicas homogeneizadoras, debido a que al imperio del tipo de vida del animal laborans, bajo el cual el humano queda reducido a mero miembro de la especie, es decir, sin identidad que le distinga de los demás como un ser único e irrepetible. Dicho en otros términos, cuando hablamos de un animal laborans cuya condición de vida es de superfluidad, nos referimos a un humano imposibilitado de aparecer frente a otros y, por tanto, de distinguirse en su aporte al artificio, con lo cual su identidad permanece oculta y carece de toda relevancia. Específicamente, lo que Arendt quiere destacar de una condición de vida de este tipo, es que ella refleja un daño del vínculo humano-mundo a tal extremo, que aquel ya no puede pertenecer a él desde la contribución a su creación y permanencia, lo que pone en peligro tanto la vida de los individuos carentes de dignidad, como la durabilidad del mundo.

El escenario descrito es condición de posibilidad del advenimiento de los totalitarismos, puesto que en ausencia de agentes identificables de la acción, el mundo es gobernado ya sea por dinámicas procesuales que responden al movimiento inherente de las ideologías o al gobierno de nadie 
anclado en el interés común. Lo que ambos gobiernos comparten es la total ausencia de realización de la dignidad humana y, aunque podría pensarse que el gobierno de nadie - propio de las democracias representativas en que gobiernan burocracias bajo cuyo paraguas desaparecen las identidades-, es incomparablemente menos peligroso, desde la perspectiva de Arendt, dicho gobierno puede llegar a ser más cruel y tiránico que otras formas de gobierno conocidas (Arendt, 2010: 51). En sus propias palabras:

"Hay sólo algo que parece discernible: podemos decir que el mal radical ha emergido en relación con un sistema en el que todos los hombres se han tornado igualmente superfluos. Los manipuladores de este sistema creen en su propia superfluidad tanto como en la de los demás, y los asesinos totalitarios son los más peligrosos de todos porque no les preocupa si ellos mismos resultan estar vivos o muertos, ni siquiera si alguna vez vivieron o nunca nacieron. [...] Los acontecimientos políticos, sociales y económicos en todas partes se hallan en tácita conspiración con los instrumentos totalitarios concebidos para hacer a los hombres superfluos" (Arendt, 2011: 616).

Así, una vez homogeneizada la unicidad, bajo el gobierno de nadie y en el aislamiento que resulta de la desaparición de la esfera pública, el humano experimenta su vida sólo en el marco biológico dado por el ciclo laborconsumo. Desde la lectura propuesta aquellas críticas de intérpretes que, como Georg Kateb, no comparten la distancia de Arendt respecto a las democracias representativas (Kateb, 1984: 115), pierden fuerza. A lo ya expuesto cabe agregar que el aislamiento y la superfluidad o ruptura del vínculo humanomundo, característicos del modo de vida del animal laborans no sólo es, a juicio de la pensadora, la precondición de las tiranías, sino además un estado de esclavitud en el cual el humano vive bajo la tortura de la necesidad (Arendt, 2010: 137).

En mi lectura y a partir de los argumentos expuestos, la existencia de dispositivos homogeneizantes, presentes tanto en las democracias que antecedieron a los totalitarismos, como en las democracias de la actualidad, explica las enormes limitaciones de un régimen que, anclado en derechos formales universales, afirma una cierta concepción de dignidad humana a partir de la cual sería posible poner freno a las soluciones totalitarias. De ahí que, a mi juicio, interpretaciones como la de Seyla Benhabib, respecto a que las causas del totalitarismo estarían ligadas a la imposibilidad de las democracias de defender dichos derechos (Benhabib, 1996), no develen los fundamentos de la hermenéutica que Arendt nos ofrece. Y es que la ausencia de mundo 
que deviene de la atomización social es una condición que hayamos en ambas épocas históricas. Según las observaciones de Arendt, los movimientos totalitarios atrajeron a quienes, desde el individualismo filisteo, habían abandonado el mundo en pos de la consecución de intereses personales. La pensadora describe la situación en los siguientes términos:

"El hombre-masa al que Himmler organizó para los mayores crímenes en masa jamás cometidos en la historia presentaba las características del filisteo más que las del populacho y era el burgués que, entre las ruinas de su mundo, sólo se preocupaba de su seguridad personal y que, a la más ligera provocación, estaba dispuesto a sacrificarlo todo, su fe, su honor y su dignidad. Nada resultó tan fácil de destruir como la intimidad y la moralidad privada de quienes no pensaban más que en salvaguardar sus vidas privadas. Tras unos pocos años de permanencia en el poder y una sistemática coordinación, los nazis pudieron afirmar con justicia: "El único hombre que en Alemania es todavía una persona particular es alguien que está dormido" (Arendt, 2011: 471).

Del párrafo citado, se sigue que la homogenización llevada a su grado máximo, es uno de los objetivos más claros del totalitarismo que no sólo destruye toda particularidad desde la propaganda, sino que además, busca la eliminación de toda capacidad de convicción personal (Arendt, 2011: 627). Arendt se extiende sobre este tema en su descripción de los campos de concentración donde la autora vincula el ejercicio del poder total a la muerte de la individualidad.

"La paradoja que implica la pérdida de los derechos humanos es que semejante pérdida coincide con el instante en el que una persona se convierte en un ser humano en general -sin una profesión, sin una nacionalidad, sin una opinión, sin un hecho por el que identificarse y especificarse- y diferente en general, representando exclusivamente su propia individualidad absolutamente única, que, privada de expresión dentro de un mundo común y de acción sobre éste, pierde todo su significado" (Arendt, 2011: 427).

Conviene detenerse en la discusión sobre la existencia de derechos humanos, puesto que, en mi perspectiva, Arendt nos invita a repensar la democracia, justamente, desde una revisión de las consecuencias implicadas en la mera formalidad de los mismos. 
Mi lectura respecto a la problemática implicada en el quiebre de los derechos humanos que tanto hoy como a principios del siglo XX prometen salvaguardar la dignidad humana, se distancia de otras interpretaciones como la de Benhabib y la de Julia Kristeva.

En The reluctant modernism of Hannah Arendt, Benhabib sostiene que la génesis de los totalitarismos se halla tanto en la incapacidad histórica de los estados-nación de defender los derechos universales del hombre, como en los patrones morales y psíquicos de racismo originados por las conquistas imperiales (Benhabib, 1996: 78).

Kristeva, por su parte, también vincula el origen de los totalitarismos al fracaso de la defensa de los derechos del hombre y al rompimiento de la igualdad ante el estado, aunque pone mayor énfasis en la situación de los apátridas e inmigrantes y en el resquebrajamiento de la homogeneidad, que implicó su aparición en democracias como la francesa (Kristeva, 1999: 134).

Sin embargo, y teniendo a la vista los argumentos expuestos a lo largo de esta primera sección, cabe cuestionar si es que el resquebrajamiento de los derechos humanos es el problema de fondo o, en realidad, sólo una manifestación más del daño producido por la homogenización ya descrita. En mi interpretación, la crítica arendtiana no apunta a las incapacidades de los gobiernos para proteger a sus ciudadanos a partir de una defensa de sus derechos, sino a su falta de realización en una esfera pública donde el humano realiza su condición de pluralidad, distinguiéndose de sus iguales bajo el marco de la isonomía ya explicada.

Así, desde una lectura que sitúa el pensamiento arendtiano en la corriente de Tocqueville, la homogenización reemplaza a la igualdad política y los derechos humanos, entendidos como verdades autoevidentes, las cuales sólo sirven de base a los espejismos democráticos que aquejan no sólo a las democracias de principios de siglo XX, sino también a las democracias actuales. La metáfora de los espejismos democráticos es usada por Arendt para explicar la situación política que fue condición de posibilidad del surgimiento de los movimientos totalitarios y refiere, específicamente, al espejismo en que estaban sumidas aquellas democracias que creyeron poder prescindir de las masas políticamente indiferentes y afirmar, al mismo tiempo, su legitimidad (Arendt, 2011: 440).

En síntesis, el argumento de la pensadora, apunta directamente a la imposibilidad de pertenecer al mundo desde la unicidad de cada quien que, 
una vez dañada, deja al humano en un estado de homogeneidad, en cuyo marco las vidas de los ciudadanos se torna irrelevante. A modo de ejemplo, Arendt señala que ya en 1929 Hitler se enorgullecía ante la "grandeza del movimiento" la cual, en palabras del líder nazi, se observaba por el hecho de que setenta mil hombres,

“[...] 'han constituido exteriormente casi una unidad, que realmente estos hombres son uniformes no sólo en ideas, sino que incluso su expresión facial es casi la misma. Mirad esos ojos alegres, ese entusiasmo fanático, y descubriréis... cómo cien mil hombres de un movimiento se convierten en un solo tipo"' (Arendt, 2011: 565).

Arendt aborda las consecuencias de la homogenización que, en sus términos, implica uniformar haciendo de todos los humanos lo mismo y advierte que cuandose reduce al mínimo "el fondo oscuro de la diferencia", atentando contra "el inquietante milagro contenido en el hecho de que cada uno de nosotros esté hecho como es, singular, único, incambiable", la vida pública y su ley de la igualdad se habrán impuesto por completo, infringiéndose a sí misma el castigo de la petrificación (Arendt, 2011: 426). La pensadora plantea que la petrificación es el último estadio de un proceso que termina en el ejercicio del poder total, propio de los regímenes totalitarios. Dicho poder, sólo existe donde los humanos no son más que marionetas de reflejos condicionados cuya capacidad de comenzar algo nuevo y de aportar al mundo como artificio, ha sido destruida. De ahí que si en las democracias persisten los dispositivos homogeneizantes y la inexistencia de una esfera pública con el consecuente aislamiento de los individuos, se esté construyendo, de manera involuntaria, el camino para las soluciones totalitarias.

En suma, la propuesta arendtiana sugiere que sólo a partir de la realización de la condición humana de pluralidad de la cual surge la esfera pública, es posible contener las tormentas totalitarias. Y es que, únicamente, la existencia plural, en medio de la que todo individuo tiene voz y espacio para expresar su perspectiva actuando en consuno con otros para aportar al artificio, es posible evitar un abandono del mundo que conduce a su desertificación. En consecuencia, podemos afirmar con Arendt, que cuando las vidas de millones transcurren circunscritas a las fronteras de la privacidad, estamos ante la realización de la doble amenaza de la "nada" y del "nadie", es decir, del desierto que no sólo arrasa con las vidas de sus habitantes aislados, sino además con la existencia misma del mundo (Arendt, 2006: 507). 
Sin embargo, la esfera pública arendtiana anclada en una clara distinción entre lo público, lo social y lo privado, se nos presenta como un ideal difícil de alcanzar. No obstante, el ejercicio de pensar sobre ella nos permite comprender parte importante de las dificultades que enfrentan las democracias representativas modernas y contribuir en pos de un cambio que desarticule los dispositivos homogeneizantes e impida el advenimiento del totalitarismo. Sobre la esfera pública arendtiana profundizo en la sección que sigue.

\section{Pluralidad, conditio per quam...}

Desde una visión arendtiana, polis y pluralidad son inescindibles, puesto que no sólo la polis es resultado de la condición humana de pluralidad, sino que y, al mismo tiempo, constituye su condición de posibilidad (Arendt 2010: 22).

Para la pensadora, la condición humana de pluralidad no refiere simplemente a una diversidad entre individuos o al pluralismo observable al interior de las sociedades, sino a un segundo nacimiento, el cual se realiza cuando nos insertamos en el mundo humano -con palabra y acto-, donde además de confirmar y asumir el hecho de nuestra original apariencia física, llegamos a "vivir como [un] ser distinto y único entre iguales" (Arendt, 2010: 201-202). La interpretación arendtiana de la experiencia griega sirve para aclarar las ideas expuestas:

"Aquí de lo que se trata más bien es de darse cuenta de que nadie comprende adecuadamente por sí mismo y sin sus iguales lo que es objetivo en su plena realidad porque se le muestra y manifiesta siempre en una perspectiva que se ajusta a su posición en el mundo y le es inherente. Sólo puede ver y experimentar el mundo tal como éste es 'realmente' al entenderlo como algo que es común a muchos, que yace entre ellos, que los separa y los une, que se muestra distinto a cada uno de ellos y que, por este motivo, únicamente es comprensible en la medida en que muchos han hablado entre sí sobre él, intercambian sus perspectiva (Arendt, 2008: 174).

La fenomenología política arendtiana, nos permite comprender el sentido ulterior de la política y la esfera pública que le es constitutiva para la existencia de un mundo en el que cada cual aparece desde la unicidad frente a sus iguales para ser visto y oído por otros, distinguiéndose de cada quien. Cabe agregar que en el mundo como artificio que es hogar para la condición de pluralidad, nadie es reemplazable, puesto que, como lo plantea en la cita 
anterior, cada una de las perspectivas constituye la realidad común desde los significantes compartidos.

En este punto es fundamental profundizar en la isonomía o igual libertad, en cuya ausencia la esfera pública que sirve a la distinción de cada quien, desaparece. Ello porque sólo podrán aparecer y revelar su identidad aquellos que compartan el espacio que se configura desde un tipo de igualdad anclada en leyes cuya función no sea reducir lo diverso, sino que autorizar "la posibilidad de las palabras y las acciones" (Arendt, 1993: 22). En contraste, bajo la desertificación que resulta de los dispositivos homogeneizantes, no hay mundo común, puesto que cada quien se encuentra preso por la subjetividad de su propia experiencia, la que sigue siendo singular aunque se repita y multiplique innumerables veces. Estamos ante la consumación de la amenaza que anticipa la destrucción del mundo común, el cual, a juicio de Arendt, "ha llegado cuando se ve sólo bajo un aspecto y se le permite presentarse únicamente bajo una perspectiva" (Arendt, 2010: 67). De lo planteado se sigue que los dispositivos homogeneizantes no sólo ponen en peligro las vidas humanas, sino además, la durabilidad del mundo. Sobre ella, profundizaré en lo que sigue, con el fin de mostrar con mayor claridad, el vínculo entre la condición humana de pluralidad y la esfera pública.

Los lineamientos centrales del pensamiento arendtiano en torno a la durabilidad del mundo recorren el tejido de las actividades productoras de una realidad específicamente humana (mundo como artificio), en tanto resulta de la liberación del determinismo biológico en que se hallan todos los seres vivos. Sin embargo, no es cualquier actividad la que contribuye a la construcción y durabilidad del mundo. De las tres condiciones que conforman la vita activa, sólo dos de ellas son configuradoras del mundo común: la creación del homo faber y la significación del humano de acción. Ellas producen los objetos que - por su durabilidad- devienen en condiciones de la vida humana, es decir, en el mundo como artificio que no está, como la Tierra, dado naturalmente, sino que responde a la voluntad y quehacer de quienes lo integran (Arendt, 2010: 23). Me detendré en cada una de ellas con el fin de aclarar el modo en que realizan su contribución.

En el caso del fabricante u homo faber, la relevancia de su actividad radica en que produce aquellos objetos de uso que proveen de una estabilidad al mundo construido con los materiales de la tierra, artificio que perdura frente al movimiento siempre cambiante de las vidas humanas y del proceso natural del que fueron sacadas (Arendt, 2010: 190). La pensadora explica que, a pesar de su tendencia a decaer producto del uso y del desgaste propios del paso del 
tiempo, el adecuado uso de las cosas fabricadas por el homo faber "no las hace desaparecer y dan al artificio humano la estabilidad y solidez sin las que no merecerían confianza para albergar a la inestable y mortal criatura que es el hombre" (Arendt, 2010: 157).

Así, desde la estabilidad dada por su durabilidad, los objetos del homo faber condicionan la vida humana al establecerse como una comunidad de cosas que nos agrupa y relaciona (Arendt, 2010: 64). Dicho condicionamiento, que jamás es absoluto, está vinculado a la identidad de quienes habitan el artificio. Arendt pone el énfasis en que el carácter de uso de dichos objetos y la permanencia en el tiempo de los modelos que anteceden a su fabricación, los distingue de la producción destinada al consumo, propia del animal laborans. $\mathrm{Y}$ es que su presencia y durabilidad permiten a los humanos, en un período amplio de tiempo, recuperar su unicidad, es decir, su identidad, al relacionar su siempre cambiante naturaleza, con los mismos objetos y del mismo modo para los que éstos fueran concebidos (Arendt, 2010: 158).

Pero el homo faber no sólo fabrica cosas de uso, sino que además aquellos objetos - monumentos, escritos poéticos e historiográficos- que sirven al hombre de acción en tanto permiten el recuerdo de sus aportes al mundo como artificio, realizados en lo inmaterial, es decir, desde la acción y la palabra (Arendt, 2010: 191).

Y si el mercado de cambio es el lugar que ocupa el homo faber en el mundo, el lugar del humano de acción es la esfera pública, donde aparece frente a los demás, con quienes en acción conjunta aportará a la realidad creando instituciones, leyes, realizando gestas heroicas, y contribuyendo -desde su singular perspectiva- al sentido común sobre el bien y el mal, lo justo y lo injusto. Así, desde una perspectiva arendtiana puede afirmarse que la esfera pública es el origen de la realidad y que la vida privada del animal laborans está, justamente privada de ella. Esta idea es recurrente en sus textos donde la pensadora sostiene que "[p] ara nosotros, la apariencia -algo que ven y oyen otros al igual que nosotros- constituye la realidad” (Arendt, 2010: 59).

Así, la realidad y confiabilidad del mundo humano descansan principalmente en el hecho de que estamos rodeados de cosas más permanentes que la actividad que las produce, y potencialmente incluso más permanentes que las vidas de sus autores. En consecuencia, la vida humana, en la medida en que construye el mundo, se encuentra en constante proceso de transformación, y el grado de mundaneidad de las cosas producidas depende de su mayor o menor permanencia en el propio mundo (Arendt, 2010: 109). 
En suma, el mundo como artificio resulta tanto de los objetos producidos por el homo faber, como de las historias constitutivas de la trama de las relaciones humanas y sus protagonistas. Es en este mundo donde pueden ser contenidos los asuntos humanos y, en consecuencia, no hay espacio para los dispositivos homogeneizantes. En consecuencia, sólo en un mundo donde exista una esfera pública vigorosa, que sirva a la distinción, las tormentas totalitarias son impensables. Ello, porque, como expliqué en la sección anterior, los totalitarismos requieren de la previa atomización de los individuos, de su aislamiento y consecuente homogeneidad para surgir entre los vestigios de lo que otrora, fuera el mundo común.

De la defensa arendtiana sobre nuestra condición de pluralidad se sigue que, para la pensadora, a diferencia de teóricos políticos como Hobbes, Rousseau, Maquiavelo, Locke o Smith, por mencionar algunos, no existe una naturaleza humana común a partir de la cual puedan explicarse y ordenarse los asuntos humanos. Desde las antípodas de todo tipo de idea a priori sobre el humano, sus limitaciones y capacidades, la autora nos muestra que somos iguales únicamente en cuanto a que somos todos distintos, y que es esa condición la que nos permite fundar un modo de coexistencia anclado en la dignidad. De modo más específico, en lo que respecta al vínculo entre la condición de pluralidad y la constitución de la esfera pública, Arendt afirma:

"La acción sería un lujo innecesario, una caprichosa interferencia en las leyes generales de la conducta, si los hombres fueran de manera interminable repeticiones reproducibles del mismo modelo, cuya naturaleza o esencia fuera la misma para todos y tan predecible como la naturaleza o esencia de cualquier otra cosa. La pluralidad es la condición de la acción humana debido a que todos somos lo mismo, es decir, humanos, y por tanto nadie es igual a cualquier otro que haya vivido, viva o vivirán" (Arendt, 2010: 22).

En lo que respecta al discurso que es propio del humano de acción, la pensadora plantea que no es una mera herramienta de comunicación o información y, por ello, no responde a los criterios de la racionalidad mediofin del homo faber. Arendt afirma -retrotrayéndose a la polis griega- que el discurso político revela la cualidad de ser distinto de quien lo pronuncia y, por tanto, excede los fines de autodefensa o búsqueda de intereses que podrían lograrse en la muda violencia (Arendt, 2010: 203). La importancia que Arendt atribuye a dicho carácter revelador nos conduce directamente al modo en que concibe la política y la esfera pública que le es propia. En ella el humano se reúne con sus congéneres a partir de su condición de iguales, lo que les 
permite entenderse y anticipar las necesidades futuras. Pero, tal como afirma la pensadora, si no fuésemos todos distintos, el discurso y la acción serían innecesarios. Bastaría con signos o sonidos que permitiesen la consecución de objetivos comunes, desde una racionalidad instrumental que dispone de los medios apropiados (Arendt, 2010: 200).

Arendt, distingue claramente la acción de la fabricación, en la medida que a partir de ella se realiza la condición humana de pluralidad y, por tanto, su fundamento es la revelación del agente, como miembro único e irrepetible del artificio. Ese es uno de los motivos por el cual pone énfasis en que la acción debe vincularse claramente a un "quién", es decir, a un agente que resulte visible para otros.Sólo así se realiza el aporte que confirma la dignidad humana y nutre el tejido de las relaciones humanas, de manera que un pasado de agentes identificables por sus gestas, sirva de iluminación al presente y proyección al futuro, es decir, a la permanencia del mundo. Este es el origen de su crítica a la aplicación de leyes estadísticas a la historia, puesto que, a su juicio, en la medida que omiten los acontecimientos y a sus agentes, destruyen el pleno significado de la misma (Arendt, 2010: 53-54). Por tanto, la uniformidad estadística en tanto ideal político de una sociedad que se haya sumergida en la rutina cotidiana, debe ser considerada -en el marco de una teoría de la homogeneidad- como uno de los dispositivos que destruyen la unicidad y contribuyen a horadar la durabilidad del mundo.

Pero además, la condición de posibilidad de la acción política es la presencia de los otros que no sólo sirven de testigos a su realización e identifican al agente, sino que participan de ella. Ese es el motivo por el que Arendt descarta la idea de soberanía propia del individualismo. En sus términos:

"El poder no es un correlato de la voluntad; pero el prejuicio de que el poder es indivisible se debe, por un lado, al error de considerarlo como un correlato natural de la voluntad y, por otro lado, a la idea acertada de que la voluntad es indivisible. La divisibilidad del poder en la división de los poderes es la mejor prueba de esto, y también es la mejor prueba de que el poder no es algo engendrado por un sujeto que quiere o por una voluntad subjetiva, sino aquello que surge entre los hombres cuando actúan juntos" (Arendt, 2006: 233).

Hemos llegado a la noción política arendtiana, la cual, en mi lectura, se funda en tres pilares centrales desde los que es posible revisar la tradición anclada en la Época Moderna. El primero refiere a la existencia de derechos que, en ausencia de la esfera pública no se realizan y, por tanto, contribuyen 
al establecimiento de un espejismo democrático, el cual es terreno fértil para las tormentas totalitarias. El segundo, dice relación con el anterior y plantea que las democracias representativas no proveen de un terreno seguro, o mundo como artificio donde la dignidad de cada uno de sus miembros pueda ser asegurada. Al contrario, dado que éstas se establecen en ausencia de una esfera pública que permita la distinción de los ciudadanos, ella misma sirve a la existencia de los dispositivos homogeneizantes. Finalmente, el tercero tiene relación con el modo en que se concibe el poder político y la confusión entre lo estatal y la esfera pública. En lo que queda, expondré algunos aspectos que aclaran este último punto.

En mi lectura, la confusión entre lo estatal y la esfera pública es resultado de la pérdida de sentido que originalmente tuvo la creación de la polis. Y lo que Arendt ha traído a la discusión es, justamente, el recuerdo no sólo del hecho de que la polis era aquel espacio de distinción ya descrito, sino además, nos ha provisto de un marco que nos permite comprender las consecuencias aparejadas a su extinción.

Así, la pensadora nos sugiere un tipo de igualdad que en lugar de estar vinculada a nociones de justicia las cuales debiesen ser satisfechas en la esfera social, donde rige el imperativo de la necesidad, se entrelaza con la libertad. El problema es que la libertad, tal como Arendt la concibe -es decir, como la experiencia del hacer y del actuar con los igualmente libres (Arendt 1996: 163-164)-, desaparece bajo la proyección de las sombras que la vida social y económica ha arrojado sobre la esfera pública. De ahí que parte importante de su obra, La condición humana, se desarrolle en torno a la victoria de la sociedad sobre la esfera pública. En este marco, el rol del estado se presenta bajo dos aspectos. El primero lo muestra como aquella estructura institucional weberiana que se reserva el monopolio de la violencia, a juicio de Arendt, antítesis de la política, cuyo eje es la persuasión y el uso de la palabra, en lugar de la violencia que en la Grecia antigua se vinculaba a los bárbaros y esclavos que carecían del discurso para persuadir. El segundo aspecto nos muestra al estado como uno de los efectos del triunfo de la sociedad sobre la esfera pública en la medida que asegura las condiciones para cada cual se entregue "libremente al desarrollo de las fuerzas productivas sociales, a la producción común de los bienes exigidos para una vida 'feliz"' (Arendt, 2008: 174). Planteado en otros términos, bajo la perspectiva arendtiana, el estado usa su fuerza para asegurar el triunfo de la condición de vida del animal laborans que sumerge al humano en el ciclo labor-consumo, bajo cuyas dinámicas, ninguno de aquellos aspectos de su unicidad tienen oportunidad de realización. 


\section{Conclusión:}

La crítica arendtiana a la noción de política que se ha desarrollado en la Época Moderna, pone en tela de juicio no sólo el modo en que comprendemos nociones fundamentales como igualdad, justicia, libertad, sino además -desde su experiencia con el totalitarismo-, nos abre la posibilidad de pensar sobre el modo en que las concebimos y el espejismo que ellas encubren, permitiendo develar los mecanismos ocultos que sirven de terreno fértil al totalitarismo. Ciertamente, bajo su mirada, lo que el mundo ha perdido es la política misma. Ello se explica desde el imperio de una cultura que promueve la homogenización del humano hasta su reducción en un mero miembro de la especie. En síntesis, desde su perspectiva, el escenario de las democracias representativas pierde su máscara y se muestra como un régimen en que la ausencia de esfera pública conduce a que nuestra concepción del poder político anclada en el monopolio de la violencia y el aislamiento de los individuos, ponga en jaque la existencia humana.

En vistas a los argumentos planteados, el vuelco que implica observar la realidad desde el prisma que nos provee la pensadora, nos conduce hacia una noción de política cuyo rol es la construcción del artificio y la contribución a su permanencia desde la realización de la condición humana de pluralidad. Sólo entonces estamos ante aquel poder específicamente político que resulta de la reunión de los humanos agrupados por el discurso y la acción. En contraste, ante la dispersión del grupo, todo poder desaparece. De ahí que no sea posible almacenarlo ni detentarlo o mantenerlo. Y es que el poder como la actividad y la libertad propios de la concepción política arendtiana, tienen en común el hecho de que su realidad está dada por la unión de palabra y acto, donde a diferencia de la tiranía, las palabras no están vacías ni "se emplean para velar intenciones, sino para descubrir realidades, y los actos no se usan para violar y destruir sino para establecer relaciones y crear nuevas realidades" (Arendt 2010: 222-223). 
Referencias bibliográficas

Arendt Hannah (2006), Diario Filosófico, Herder, Barcelona.

(2011), Los origenes del totalitarismo, Alianza Editorial, Madrid.

(2010), La condición humana, "Labor", Paidós, Buenos

Aires.

(2008), La promesa de la politica, Paidós, Barcelona.

(1993), ¿Qué es la politica?, Paidós, Barcelona.

(2009), Sobre la revolución, Alianza Editorial, Madrid.

Benhabib Seyla (1996), "The reluctant Modernism of Arendt", en The Public Sphere and Totalitarism, Sage Publications, California.

Kateb George (1984), "Modern Democracy", en Politics, Conscience, Evil, Rowman \& Allanheld, New Jersey.

Kristeva Julia (1999), Hannah Arendt, Columbia University Press, New York.

Tocqueville Alexis (2006), La democracia en América, Alianza Editorial, Madrid. 